
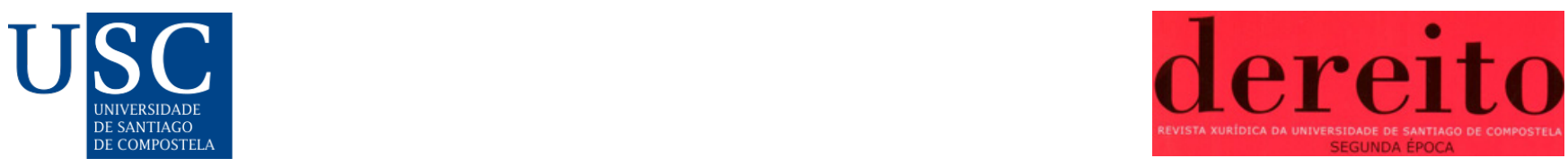

Dereito: revista xurídica da Universidade de Santiago de Compostela, 30(2), 2021. ISSN-e: 2174-0690

https://doi.org/10.15304/dereito.30.1.8037

Comentarios y crónicas

\title{
RESEÑA DEL WEBINAR COVID-19, DIGITALIZAÇAO DA SOCIEDADE E OUTROS DESAFIOS PARA O DIREITO DO CONSUMO
}

\author{
Borja del Campo Álvarez ${ }^{1, a}$ \\ ${ }^{1}$ Profesor Sustituto de Derecho Civil Universidad de Oviedo, España \\ a campoborja@uniovi.es
}

El pasado 12 de febrero de 2021 se celebró virtualmente el seminario web "COVID-19, digitalización de la sociedad y otros desafíos para el Derecho de consumo". El evento, organizado por el E-tec de Jus-Gov, la Escola de Direito de la Universidade do Minho, el grupo "De Conflictu Legum" y la Facultad de Derecho de la Universidad de Santiago de Compostela, contó con la participación de reputados investigadores portugueses, españoles y brasileños.

El webinar, bajo la dirección de Mónica García Goldar -investigadora de la Facultad de Derecho de la Universidad de Santiago de Compostela- y de Anabela Gonçalves -Professora da Escola de Direito da Universidade do Minho-, supuso un enriquecedor e internacional intercambio de ideas sobre el Derecho del Consumo y los retos propios de la digitalización de la sociedad.

Con motivo de las restricciones derivadas de la pandemia, el evento se desarrolló de forma virtual. Circunstancia que no implicó, como a la postre quedó patente por el éxito de convocatoria, el más mínimo detrimento en la calidad del seminario web.

Tras las palabras de bienvenida y los correspondientes saludos institucionales en voz de la Professora da Escola de Direito da Universidade do Minho, Anabela Gonçalves, dio comienzo al primer panel moderado por Maria Miguel Carvalho, Professora da Escola de Direito da Universidade do Minho.

La primera intervención corrió a cargo de Maripaz García Rubio, Catedrática de Derecho Civil de la Universidad de Santiago de Compostela, quién muy didácticamente disertó sobre el impacto de la pandemia provocada por el COVID-19 en el Derecho de Consumo. Su exposición, marcada por la claridad y el detalle, sirvió para poner de manifiesto los nuevos escenarios que el coronavirus ha provocado en la esfera jurídica, especialmente en lo que al Derecho de Consumo se refiere.

A continuación, Anabela Gonçalves puso el enfásis en dos componentes vinculados al contrato de consumo y sus correspondientes consecuencias jurídicas. Por un lado, en todo lo relativo al carácter internacional del contrato y, de otro, en su perfil online. De hecho, su ponencia llevó por título "0 contrato de consumo internacional online".

Para cerrar este primer bloque la intervención de Isa Meireles, Assistente da Escola de Direito da Universidade do Minho, versó sobre la resolución de los contratos por motivo de la pandemia, 
suceso especialmente frecuente durante el 2020, año de mayor impacto de la crisis, y que planteó no pocos interrogantes para el Derecho de Consumo y el Derecho de Contratos.

El segundo panel, moderado por Mónica García Goldar, comenzó con la intervención de Ignacio Fernández Chacón, Profesor Ayudante Doctor de Derecho Civil de la Universidad de Oviedo. Su ponencia trató y llevó por atractivo título "Desafíos regulatorios del suministro de contenidos y servicios digitales a cambio de datos personales". Tras su exposición Luisa Cortat, Investigadora visitante na Universidade ONU FLORES, nos ilustró acerca de un tema bastante desconocido pero que supuso una reflexión muy interesante acerca de "Praticas sustentàveis e o uso de plásticos numa Europa pós-COVID-19: o nudge dos consumidores".

Para concluir el segundo y último panel de la jornada matutina, María Miguel Carvalho, docente de la Universidade do Minho, compartió con los asistentes unas cuidadas reflexiones acerca del Derecho de Marcas y el COVID-19, poniendo en solfa, una vez más, como la pandemia ha implicado una serie de profundos cambios a todo nivel y estructura.

La jornada de tarde se abrió con la ponencia de Cláudia Lima Marques, Professora da Universidade Federal do Rio Grande do Sul, quien nos aportó una visión panorámica acerca del régimen jurídico del consumidor en Brasil, el impacto sociojurídico de la pandemia en el continente latinoamericano y la actualización del Código de Defensa del Consumidor, norma de referencia de Brasil sobre esta materia.

Por su parte, Marta Carballo Fidalgo, Profesora Titular de Derecho Civil de la Universidad de Santiago de Compostela, trató muy prolijamente los principales aspectos de la Directiva 93/13/CEE sobre cláusulas abusivas. Completó, a su vez, su intervención con el análisis de la jurisprudencia más relevante del Tribunal de Justicia de la Unión Europea (TJUE) sobre la cuestión.

A continuación, Marta Otero Crespo, Profesora Contratada Doctora de Derecho Civil de la Universidad de Santiago de Compostela, realizó un examen más concreto de la jurisprudencia comunitaria al analizar el impacto de la sentencia del TJUE de 16 de julio de 2020 en los préstamos hipotecarios con consumidores. Ambas ponencias, excelentes en fondo y forma, sirvieron para conocer las novedades legislativas y jurisprudenciales más destacadas en el ámbito de la Unión Europea.

El último bloque, siguiendo la senda del tercero, versó también sobre Derecho de Consumo desde una perspectiva europea. Así, Ricardo Pazos Castro, Profesor Ayudante Doctor de Derecho Civil de la Universidad Autónoma de Madrid, abordó la problemática suscitada en torno a la transparencia del índice IRPH mediante el estudio de la aplicación de jurisprudencia europea por parte del Tribunal Supremo.

Para concluir, Nuno Manuel Pinto de Oliveira, Professor da Escola de Direito da Universidade do Minho, habló sobre la resolución del contrato de compraventa en la Directiva 2019/771. Consecuentemente, la Directiva en cuestión marcó fundamentalmente el objeto expositivo del último bloque de este webinar dedicado al Derecho del Consumo.

Tras sus brillantes intervenciones, retomó la palabra la Dra. García Goldar, organizadora del evento, para agradecer personalmente a ponentes, asistentes y organizadores el empeño ofrecido para llevar a cabo el seminario web y se congratuló, junto con los presentes, del exitoso resultado. La jornada, breve pero intensa, sirvió para acercarnos nuevamente al omnipresente Derecho del Consumo, valorar los desafíos jurídicos de la materia para las próximas décadas y examinar las consecuencias de la COVID-19. 